\title{
The history and global market of oral home-care products
}

\author{
Juliana Jobim Jardim(a) \\ Luana Severo Alves ${ }^{(b)}$ \\ Marisa Maltz' ${ }^{(c)}$
}

(a) MSc, Graduate fellow; (b) Graduate fellow; (c)PhD, Professor-Department of Social and Preventive Dentistry, School of Dentistry, Federal University of Rio Grande do Sul, Porto Alegre, RS, Brazil.

\section{Corresponding author:}

\section{Marisa Maltz}

Faculdade de Odontologia - UFRGS

Departamento de Odontologia Preventiva

e Social

Rua Ramiro Barcelos, 2492

Porto Alegre - RS - Brazil

CEP: 90035-003

E-mail:mmaltz@ufrgs.br

Received for publication on May 04, 2009

Accepted for publication on May 12, 2009

\begin{abstract}
This literature review reports the history and the current market of oral home-care products. It provides information extending from the products used by our ancestors to those currently available, as well as on the changes in the supply and consumption of these products. Although the scientific knowledge about oral diseases has improved greatly in recent years, our ancestors had already been concerned with cleaning their teeth. A variety of rudimentary products and devices were used since before recorded history, like chewing sticks, tree twigs, bird feathers, animal bones, tooth powder and home-made mouth rinses. Today, due to technological improvements of the cosmetic industry and market competition, home-use oral care products available in the marketplace offer a great variety of options. An increase in the consumption of oral care products has been observed in the last decades. Estimates show that Latin America observed a $12 \%$ increase in hygiene and beauty products sales between 2002 and 2003, whereas the observed global rate was approximately $2 \%$. A significant increase in the per capita consumption of toothpaste, toothbrush, mouthrinse and dental floss has been estimated from 1992 to 2002 , respectively at rates of $38.3 \%, 138.3 \%, 618.8 \%$ and $177.2 \%$. Pertaining to this increased supply and consumption of oral care products, some related questions remain unanswered, like the occurrence of changes in disease behavior due to the use of new compounds, their actual efficacy and correct indications, and the extent of the benefits to oral health derived from consuming more products.
\end{abstract}

Descriptors: Oral hygiene; Dental devices, home care; Dentifrices; Mouthwashes. 


\section{The history of oral home-care products}

Bacterial biofilm is a natural component of the oral environment and is compatible with health in balance situations. When biofilm accumulation on dental or gingival tissues occurs for a certain period of time and combined with others factors, it can lead to dental caries or periodontal disease - the major causes of tooth loss everywhere in the world ${ }^{1}$ and the two most common chronic human diseases. ${ }^{2}$

Although the scientific knowledge about the etiology and dynamics of the development of oral diseases has presented a great improvement in the last decades, man has tried to find ways to clean his teeth since a remote past.

A variety of oral hygiene measures has been used since before recorded history. This has been verified by excavations done all over the world, in which chewing sticks, tree twigs, bird feathers and animal bones were found.

The early history and evolution of the toothbrush has its origin in the chewing sticks used by the Babylonians as early as $3500 \mathrm{BC}$. Also known as "miswak" or "siwak", it was also an ancient pre-Islamic habit. Mohammed was an enthusiastic supporter of its use as a "purgative for the mouth". He used to report that "it makes the teeth white, clarifies the understanding, makes the breath fragrant, dries up the phlegm, strengthens the gums around the teeth, makes the glance clear, sharpens the power of the vision, opens the bowels and whets the appetite", evidencing that, for some, "miswak" was not only a personal hygiene habit but also a spiritual custom. The chewing stick was a rudimentary toothbrush used as a single agent or with tooth powder or extract of roses. ${ }^{2}$

The first true bristled toothbrush was originated in China at around 1600 AD. The first modern toothbrush was reinvented in the late $18^{\text {th }}$ and early $19^{\text {th }}$ centuries. $^{2}$ The first patent for a toothbrush was credited to H. N. Wadsworth in 1857, in the United States, but due to the high price of the hog bristle, the mass production of the product in America only started in the end of the $19^{\text {th }}$ century. As technology progressed, natural swine bristles were replaced by synthetic fibers, usually nylon. The first electric toothbrush, an attempt to offer the public a brush that could simulate the action of a manual brush, was developed in 1939 in Scotland, but did not appear on the market until the 1960s.

Ancient Greek and Roman literature had first reported the use of twigs as primitive toothpicks to remove food and debris from between the teeth. The intent of early humans was probably not to clean the teeth but simply to remove an unpleasant subjective sensation. The Greeks tended to keep these little instruments in their mouths continuously and were often referred to as "toothpick chewers". ${ }^{2}$ Around $1600 \mathrm{BC}$, the Chinese also used twigs made of trees carefully chosen from aromatic species that had the ability to clean and freshen the mouth. Wealthy citizens often carried their gold or silver toothpicks in fancy cases and used them ostentatiously at meals. Many religions, both before and after the Christian era, enjoined their adherents to practice cleanliness of the teeth using twig cuts as a tooth-pick. ${ }^{3}$

The development of toothpaste began as long ago as 300-500 BC in China and India. First attempts at tooth cleaning included using abrasives such as crushed bone, crushed egg and oyster shells. ${ }^{4}$ Tooth powder was the first noticeable advance, and was made up of elements like powdered charcoal, powdered bark, salt and some flavoring agents. ${ }^{5}$

Modern toothpastes were developed in the 1800s. As the years passed, new components were added to their formulations, as soap and chalk. In 1873 , toothpaste was firstly mass-produced. Due to advancements in synthetic detergents after World War II, the soap was replaced for emulsifying agents such as sodium lauryl sulphate and sodium ricinoleate. Fluoride was added initially in 1914, but the American Dental Association at first criticized its introduction. The ADA finally consented to the use of fluoride in toothpastes in 1960.

Besides the traditional tooth paste and brush, a great variety of home-use oral products have been developed.

A concern about the cleaning of approximal surfaces was first reported by Levi Parmly (17901859), the inventor of dental floss. ${ }^{6}$ He stated that the device should "be passed through the interstices of the teeth, between their necks and the arches of 
the gum, to dislodge that irritating matter which no brush can remove and which is the real source of distress". Dental floss made of silk was used since the $19^{\text {th }}$ century, while nylon floss was made available in the marketplace right after World War II. The difficulty of flossing explains its reduced use and makes this technique less than universal. ${ }^{2}$ Other interdental cleaning devices have been developed, such as rubber tip stimulators and interdental brushes.

The first known reference to mouth rinsing is found in Chinese medicine, around 2700 BC. Later on, in the Greek and Roman periods, mouth rinsing following mechanical cleansing became common among the upper classes, and Hippocrates recommended a mixture of salt, alum and vinegar ${ }^{2}$ while Pythagoras recognized the freshening effect of anise. $^{5}$ Different products were used for mouth rinsing over the centuries. In the 1500 s, wine or beer were used; in the late $19^{\text {th }}$ century, around 1890 , the use of essential oils was introduced among the dental care habits. ${ }^{2}$ Freshening bad breath has been the traditional use of mouth rinsing. Besides this cosmetic purpose, therapeutic mouth rinsing is now available, including fluoride, quaternary ammonium compounds and chlorhexidine.

Today, due to technological improvements of the cosmetic industry and market competition, homeuse oral care products available in the marketplace offer the consumer a wide variety of options. The toothbrush head is presented in different forms and sizes; bristles are presented in different hardness options (hard, medium, soft or extra-soft). Toothpastes are presented in different concentrations of fluoride (from formulations without this component to versions with a very high concentration of it, such as $5000 \mathrm{ppm}$ ); and special versions present natural components, such as propolis and jua, for specific purposes, as tooth bleaching, dental erosion control or to reduce sensitivity. Mouth rinses have a cosmetic or therapeutic use, just for mouth freshening or for controlling plaque, gingivitis and dental caries.

Owing to the wide variety of products available in the marketplace and the strong appeal to consumers exerted by the cosmetic industry, the consumption of oral care products has increased in the last decades. In the following section, the changes in the consumption of oral health products and their main reasons are discussed.

\section{The market of oral home-care products}

Nielsen Company ${ }^{7}$ (2004) studied the sales of hygiene and beauty products in 56 countries comprising 95\% of the world Gross Domestic Product (GDP) and $75 \%$ of the world population. They divided the Hygiene and Beauty products in 9 categories: baby products, cosmetics, hair products, paper products, oral hygiene, body hygiene and moisturizing, facial hygiene and moisturizing, sunscreen and hair removal. Although hygiene and beauty products are among the categories with the lowest sales increase in the world, around $2 \%$, they rank fourth in sales (Graph 1). And Latin America has shown larger growth rates than those of the rest of the world. The oral hygiene products market presented an increase of $12 \%$ between 2002 and 2003, as shown in Graph 2.

The consulting firm Kline \& Company $^{8}$ (2004) studied the sales of oral care products in 16 countries. According to this study, Brazil occupied in 2004 the $10^{\text {th }}$ position in sales of oral care products. The sales in Brazil were ahead of countries with higher economic power, like Canada and Spain, and countries in Latin America like Argentina (Table 1).

The consumption of toothpaste and toothbrush per inhabitant per year is respectively $90 \%$ and $110 \%$ higher in Brazil compared with Argentina, ${ }^{9}$ as shown in Table 2. In 2004, the sales of oral health products in Brazil was five times the sales of these products in Argentina, even though Argentina showed a sales increase 8 times higher than that of Brazil from 2003 to 2004. The consumption of toothpaste, toothbrush, mouthrinse and dental floss had increased significantly, as can be seen in Table 3 (absolute values) and Table 4 (average per capita).

Comparing the consumption per capita of these products, an increase of $38.3 \%$ in toothpaste, $138.3 \%$ in toothbrush and $177.2 \%$ in dental floss can be noticed from 1992 to $2002 .{ }^{9}$ Of all the oral care products, mouthrinse is the one that presented during this period the most outstanding increase in sales: $618.5 \%$. This could be due to the fact that the 

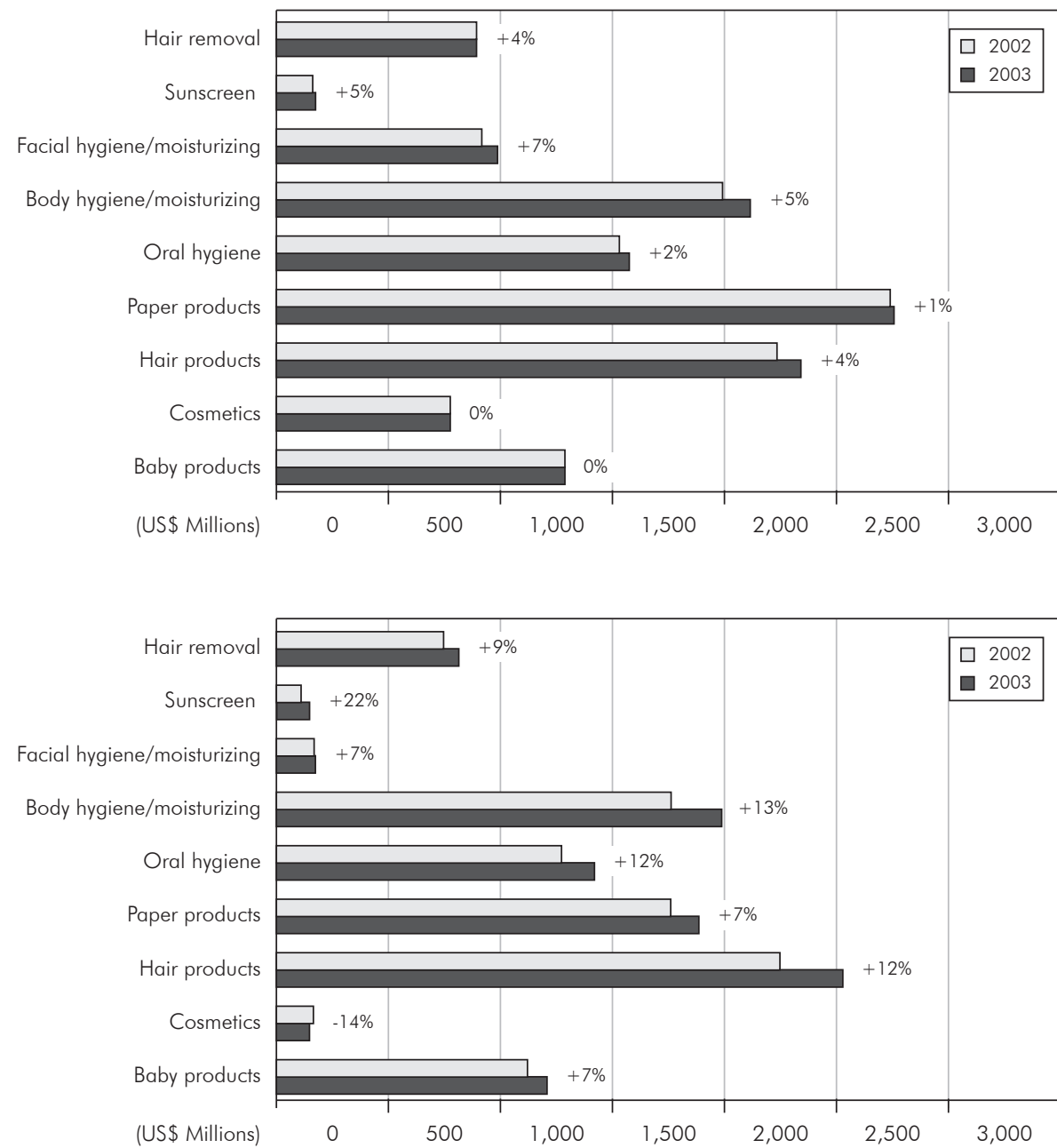

Graph 1 - World sales of Hygiene and Beauty products. Growth by basket of products (number of countries covering the categories in each basket of products). ${ }^{7}$
Graph 2 - Sales of Hygiene and Beauty products in Latin America. Growth by basket of products (number of countries covering the categories in each basket of products). ${ }^{7}$ supply of these products was significantly enhanced in the past 10 to 15 years. New mouthrinses for biofilm control and caries prevention, using different active compounds, such as essentials oils, natural products (propolis and jua), cetylpyridinium chloride and fluoride are available at lower prices, and are produced by a larger variety of companies. The newest product release on the marketplace is a mouthrinse for dental bleaching. There is no data concerning the increase in over-the-counter dental bleaching products in Brazil; however, global data from Nielsen ${ }^{7}$ (2004) showed a $48 \%$ sales increase from 2002 to 2003.

According to internal estimates from ColgatePalmolive (unpublished data), toothpaste is in $99.9 \%$ of Brazilian homes. Each Brazilian consumes, per year, 1.67 toothbrush, 126 milliliters of mouthrinse and 18.8 meters of dental floss (which means 5.1 centimeters per day). Comparing these recent data with those showed previously, we can observe that the consumption of toothbrush increased from 1.12 in 2002 to 1.67 in 2009.

Current data from ABIHPEC ${ }^{10}$ (2008) shows that the market of oral care products has increased from 2002 to 2006 in Brazil, when it was handling around US $\$ 746.1 \times 10^{3}$, as shown in Graph 3. As to the sales share in 2006 , toothpaste represented $66 \%$, dental floss, $21 \%$, mouthrinse, $9 \%$ and toothbrush, $4 \%$ (Graph 4). ${ }^{10}$

In general, four reasons for this sales increase of oral care products in Brazil were pointed out by ABIHPEC $^{10}$ (2004) and confirmed by Nielsen ${ }^{7}$. The reasons are:

1. Women's increasing participation in the labor market: this fact created a need for practical products, in addition to an increase in the pur- 
chasing power of the household. Hence, products that presented a faster and easier way of use, like disposable dippers, had their sales increased. Dental home bleaching products, for example, are also time- and moneysaving alternatives to a dental visit.

Table 1 - Oral care products sales in $2004 .^{8}$

\begin{tabular}{c|c|c}
\hline Ranking & Country & Sales (US\$ millions) \\
\hline 1 & USA & 2,738 \\
\hline 2 & China & 1,335 \\
\hline 3 & Germany & 1,021 \\
\hline 4 & Japan & 959 \\
\hline 5 & Russia & 863 \\
\hline 6 & United Kingdom & 639 \\
\hline 7 & India & 617 \\
\hline 8 & Italy & 600 \\
\hline 9 & France & 592 \\
\hline 10 & Brazil & $\mathbf{5 0 6}$ \\
\hline 11 & Mexico & 393 \\
\hline 12 & South Korea & 360 \\
\hline 13 & Canada & 234 \\
\hline 14 & Spain & 207 \\
\hline 15 & Poland & 185 \\
\hline 16 & Argentina & 75 \\
\hline
\end{tabular}

Table 3 - Consumption of toothpaste (ton), toothbrush (unit), mouthrinse (ton) and dental floss (unit) in Brazil between 1992 and 2002.9

\begin{tabular}{c|c|c|c|c}
\hline \multirow{2}{*}{ Year } & \multicolumn{4}{|c}{ Product } \\
\cline { 2 - 5 } & Toothpaste & Toothbrush & Mouthrinse & Dental Floss \\
\hline 1992 & 63,200 & 71,688 & 825 & 15,350 \\
\hline 1993 & 62,980 & 82,693 & 843 & 16,032 \\
\hline 1994 & 69,820 & 101,065 & 1,309 & 17,783 \\
\hline 1995 & 67,394 & 111,758 & 2,131 & 22,635 \\
\hline 1996 & 77,455 & 113,481 & 2,890 & 22,995 \\
\hline 1997 & 84,629 & 122,601 & 3,569 & 22,921 \\
\hline 1998 & 90,163 & 137,064 & 4,258 & 25,881 \\
\hline 1999 & 96,151 & 139,546 & 3,577 & 30,319 \\
\hline 2000 & 95,466 & 151,921 & 3,448 & 31,250 \\
\hline 2001 & 104,075 & 184,768 & 5,438 & 45,000 \\
\hline 2002 & 100,308 & 196,264 & 6,773 & 48,954 \\
\hline
\end{tabular}

2. The use of cutting-edge technology by the industry, leading to increased productivity and, consequently, lower prices to consumers.

3. Constant release of different products, in an attempt to meet the consumers' needs for new and interesting formats. An example is the addition of the strip format to the mouth-refreshing category. Innovations in oral care products are constantly being released onto the marketplace, like combinations of dentifrice, mouthrinse, dental bleaching and desensitizer in a single product.

4. An increase in life expectancy, which leads to an increase in the proportion of elder consumers. This share of the population is growing faster in Latin America than in the rest of the world. The increasing desire to preserve a youthful ap-

Table 2 - Average consumption of toothpaste $(\mathrm{kg} /$ inhabitant) and toothbrush (unit/inhabitant), per year, in selected countries in 2002.?

\begin{tabular}{c|c|c}
\hline Country & $\begin{array}{c}\text { Consumption of toothpaste } \\
\text { (kg/inhabitant) }\end{array}$ & $\begin{array}{c}\text { Consumption of } \\
\text { toothbrush (unit/ } \\
\text { inhabitant) }\end{array}$ \\
\hline Argentina & 0.21 & 0.41 \\
\hline Canada & 0.26 & 0.88 \\
\hline Mexico & 0.30 & 0.69 \\
\hline Brazil & 0.40 & 0.86 \\
\hline
\end{tabular}

Table 4 - Average consumption of toothpaste (gram), toothbrush (unit), mouthrinse (gram) and dental floss (unit) per capita in Brazil between 1992 and 2002.'

\begin{tabular}{c|c|c|c|c}
\hline \multirow{2}{*}{ Year } & \multicolumn{4}{|c}{ Product } \\
\cline { 2 - 5 } & Toothpaste & Toothbrush & Mouthrinse & Dental Floss \\
\hline 1992 & 415.2 & 0.47 & 5.4 & 0.101 \\
\hline 1993 & 407.6 & 0.54 & 5.5 & 0.104 \\
\hline 1994 & 445.4 & 0.64 & 8.4 & 0.113 \\
\hline 1995 & 423.8 & 0.70 & 13.4 & 0.142 \\
\hline 1996 & 480.3 & 0.70 & 17.9 & 0.143 \\
\hline 1997 & 517.7 & 0.75 & 21.8 & 0.140 \\
\hline 1998 & 544.2 & 0.83 & 25.7 & 0.156 \\
\hline 1999 & 572.6 & 0.83 & 21.3 & 0.180 \\
\hline 2000 & 560.9 & 0.89 & 20.3 & 0.184 \\
\hline 2001 & 603.7 & 1.07 & 31.5 & 0.261 \\
\hline 2002 & 574.4 & 1.12 & 38.8 & 0.280 \\
\hline
\end{tabular}




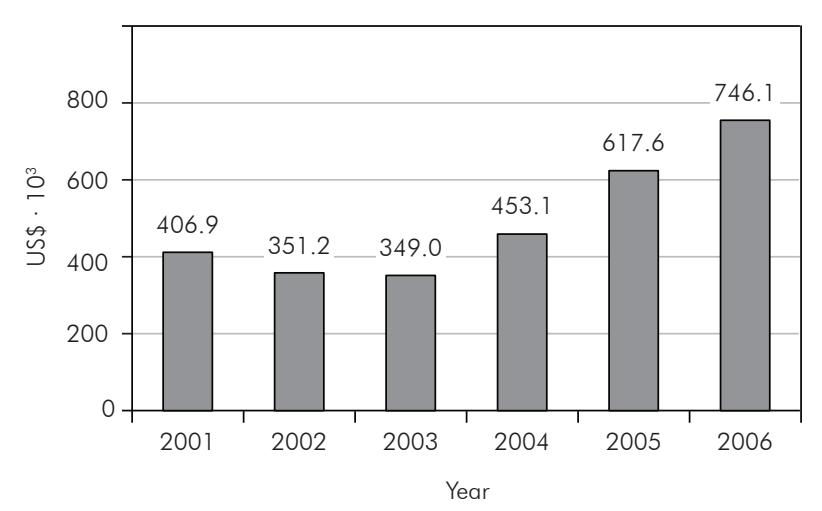

Graph 3 - Sales of oral care products from 2001 to 2006 in Brazil. Values are expressed in dollars. ${ }^{10}$

pearance is reflected by an enhancement in the development of anti-aging products. The sales increase of dental bleaching agents is also a reflection of this situation.

Since remote times, our ancestors were concerned with cleaning their teeth and keeping their mouths fresh and healthy. They developed a variety of rudimentary devices and products, which ultimately led to today's availability of a wide range of oral home-care products. A large increase has been observed in the consumption of these products in a short time interval: $12 \%$ over one year in Latin

\section{References}

1. Baelum V, Luan WM, Chen X, Fejerskov O. Predictors of tooth loss over 10 years in adult and elderly Chinese. Community Dent Oral Epidemiol. 1997;25:204-10.

2. Fischman $S$. The history of oral hygiene products: how far have we come in 6000 years? Periodontol 2000. 1999;15:7-14.

3. Campbell JM. Dentistry then and now. $2^{\text {nd }}$ ed. Edinburgh: Privately Printed for the author; 1963.

4. Ring ME. História ilustrada da Odontologia. São Paulo: Manole; 1998.

5. Lerman S. Historia de la Odontologia y su ejercicio legal. $2^{\text {nd }}$ ed. Buenos Aires: Mundi; 1964.

6. Sanoudos M, Christen AG. Levi Spear Parmly: The Apostle of Dental Hygiene. J Hist Dent. 1999;47(1):3-6.

7. Nielsen Company. Os produtos mais quentes do mundo - informações sobre o crescimento de categorias de higiene $\&$ beleza

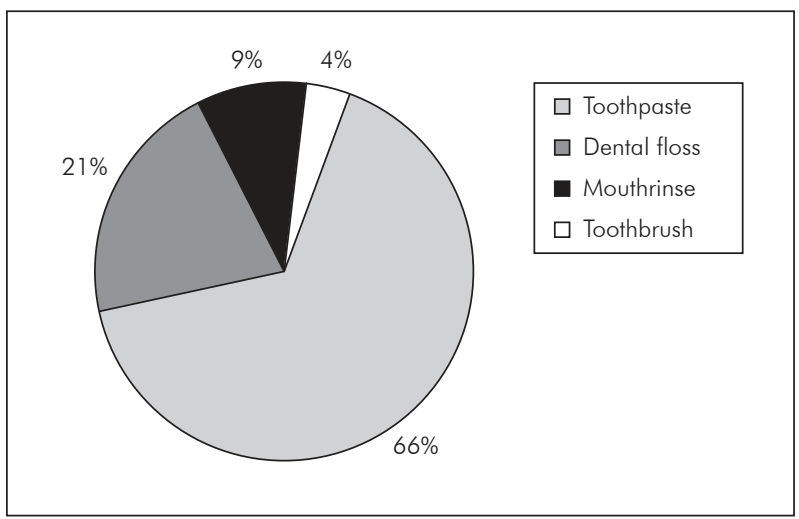

Graph 4 - Oral care products sales share in 2006 in Brazil (Source: ABIHPEC). ${ }^{10}$

America, ${ }^{7}$ for example. Some questions arise from observing the current data. Has the behavior of dental diseases changed over the time due to exposure to compounds like fluoride, antimicrobials or chlorhexidine? Do dental professionals know the actual efficacy and the correct indications of the available products? To what extent the increased supply and consumption of home-care products has actually promoted an improvement in oral health? Future investigations may answer these questions in order to guide consumers and professionals in using oral home-care products.

[online]. São Paulo: Nielsen Global Services; 2004. Available from: http://www.acnielsen.com.br.

8. Kline \& Company. Global Cosmetics \& Toiletries 2004: World Overview [online]. Kline \& Company: Business process management consulting and industry market research reports. Available from: http://www.klinegroup.com/.

9. Manfredini MA. Características da indústria de equipamentos odontológicos e de produtos para higiene bucal no Brasil entre 1990 e 2002 [Dissertação de Mestrado]. São Paulo: Coordenadoria de Controle de Doenças da Secretaria de Estado da Saúde de São Paulo; 2006.

10. Abihpec. São Paulo: Associação Brasileira da Indústria de Higiene Pessoal, Perfumaria e Cosméticos; 2008. Available from: www.abihpec.org.br. 